\title{
HORIZONTES DE UMA RELAÇÃO RURAL - URBANO NÃO CAPITALISTA: O MOVIMENTO SOCIAL COMMUNITY SUPPORTED AGRICULTURE'
}

\author{
Alanda Lopes Baptista Martins* \\ Universidade Aberta do Brasil
}

Resumo: 0 que se compreende como rural, em termos de suas instâncias empíricas e conceituais, é, ainda que de forma vaga, altamente carregado do simbolismo. No pensamento sociológico, a ideia de rural é tradicionalmente abordada em articulação direta com seu par oposto, o urbano, tal como um axioma analítico de compreensão da realidade a partir de uma relação entre dois polos. Uma infinidade de obras teóricas vem se dedicando a resolver a dificuldade, imposta pelo desafio deste mesmo axioma, de delimitação de cada uma destas esferas específicas. Seu produto conceitual, que impregna de sentidos o rural, reflete, por sua vez, perspectivas reais de comprometimento de grupos sociais específicos, bem como de suas demandas de reprodução do espaço. 0 objetivo deste artigo é trazer à tona elementos de tais narrativas históricas sobre o rural, com um enfoque sobre o modo de pensar capitalocêntrico acerca da relação rural-urbano. Defendemos a necessidade de se descortinar a gênese teórica do rural, bem como dos compromissos teóricos estabelecidos a partir de determinadas demandas e circunstâncias sociais, para uma necessária abertura a análises dedicadas a dualidade conceitual rural-urbano que apontem para outros processos sociais, em curso, e não redutiveis a racionalidade capitalista, tal como a experiência, neste texto abordada, do movimento social Community Supported Agriculture (CSA) com sua interface rural-urbano através da construção de estratégias solidárias de produção/distribuição/consumo de alimentos.

Palavras-chave: Relação rural-urbano. Novas ruralidades. Community Supported Agriculture.

\section{HORIZONS OF A NON-CAPITALIST RURAL - URBAN RELATIONSHIP. THE COMMUNITY SUPPORTED AGRICULTURE SOCIAL MOVEMENT}

Abstract: What is understood as rural, in terms of its empirical and conceptual instances, is, albeit vaguely and highly charged with symbolism. In sociological thought the idea of rural is traditionally approached in direct articulation with its opposite pair, the city, as an analytical axiom of understanding of reality from a relation between two poles. A multitude of theoretical works has been dedicated to solving the difficulty, imposed by the challenge of this same axiom, of delimiting each of these specific spheres. Its conceptual product, which impregnates the rural senses, reflects, in turn, real perspectives of commitment, of specific social groups, as well as of its demands of space reproduction. The aim of this article is to bring to the surface elements of such historical narratives about the rural, with a focus on the capital-centric way of thinking about the countryside-city relationship. We defend the need to unveil the theoretical genesis of the rural, as well as the theoretical commitments established from certain demands and social circumstances, to a necessary opening to analyzes dedicated to the rural-urban conceptual duality that point to other ongoing social processes, and not reducible to capitalist rationality, such as the experience in this text of the social movement Community Supported Agriculture (CSA) with its rural-urban interface through the construction of solidarity strategies of production/distribution/consumption of food.

Keywords: Rural/urban relationship. New ruralities. Community Supported Agriculture.

\section{HORIZONTES DE UNA RELACIÓN RURAL - URBANO NO CAPITALISTA: EI MOVIMIENTO SOCIAL COMMUNITY SUPPORTED AGRICULTURE}

Resumem: La comprensión de lo rural, en términos de sus instancias empíricas y conceptuales, está altamente cargado de simbolismo, aunque de forma vaga. En el pensamiento sociológico, la idea de lo rural es tradicionalmente abordada en articulación directa con su par opuesto, lo urbano, tal como un axioma analítico de comprensión de la realidad, a partir de una relación entre dos polos. Una infinidad de obras teóricas se han dedicado a resolver la dificultad impuesta por el desafío de este mismo axioma, la delimitación de cada una de estas esferas especíicas. El producto conceptual que impregna de sentidos lo rural, refleja perspectivas reales de compromiso de grupos sociales específicos, así como de sus demandas por la reproducción del espacio. El objetivo de este artículo es discutir elementos de tales narrativas históricas sobre lo rural, con un enfoque sobre el modo de pensar capitalocéntrico acerca de la relación rural-urbano. Defendemos la necesidad de desvelar la génesis teórica de lo rural, así como de los compromisos teóricos establecidos a partir de determinadas demandas y circunstancias sociales, para una necesaria apertura de los análisis dedicados a la dualidad conceptual rural-urbano que apunten para otros procesos sociales en curso, y que no pueden ser reducidos a la racionalidad capitalista. La experiencia abordada en este texto, el movimiento social Community Supported Agriculture (CSA) con su interfaz rural-urbano a través de la construcción de estrategias solidarias de producción/distribución/consumo de alimentos nos da una oportunidad de abrir este debate.

Palabras clabe: Relación rural-urbano. Nuevas ruralidades. Community Supported Agriculture.

${ }^{\top}$ A presente discussão apresenta parte das reflexões desenvolvidas na Tese de Doutorado intitulada: Agricultura Apoiada pela Comunidade ou Comunidade Apoiada pela Agricultura? A relação campo-cidade pela ética da solidariedade, realizada pelo Programa de Pós-Graduação em Geografia da Universidade Federal Fluminense.

*Doutora em Geografia pela Universidade Federal Fluminense. Pesquisadora do Laboratório de Estudos Sobre Movimentos Sociais e Territorialidades (LEMTO-UFF) e Professora da Universidade Aberta do Brasil/FUNDAÇÃO CECIERJ/CEDERJ, vinculada ao Departamento de Geografia da Universidade do Estado do Rio de Janeiro. Polo Nova Friburgo. Endereço: Rua José Pires Barroso, S/Nº, bairro Olaria, Nova Friburgo (RJ). ORCID: 0000-0002-2063-4890. E-mail: alandalopes@yahoo.com.br 
Introdução

Em que consiste a particularidade específica disto que chamamos de rural, em termos de suas instâncias empíricas e articulações conceituais? No pensamento sociológico, a ideia de rural é tradicionalmente abordada em articulação direta com seu par oposto, o urbano (Favareto, 2007; Martins, 1986; Wanderley, 2000). Deste axioma analítico de compreensão da realidade a partir da relação entre dois polos, desdobraramse nas ciências sociais diferentes propostas de compreensão da particularidade destes espaços.

Segundo abordagens clássicas, concepções teóricas e empíricas balizadoras do que se compreende como rural e como urbano abrigariam não apenas paisagens que remetem à ausência ou à presença de uma infraestrutura determinada por uma divisão espacial do trabalho agrícola e industrial, mas, ainda, culturas e visões de mundo em suas respectivas singularidades (Martins, 1986; Wanderley, 2000; Bell, 1966; Murdoch, 2006; Sposito; Whitacker, 2006; Carneiro, 1998; Favareto, 2007).

Compartilhamos da perspectiva de que tal compreensão congrega categorias social e cientificamente construídas em situações determinadas, e não categorias autocontidas a serem consideradas num esquema interpretativo. Por outro lado, também não consideramos frutífero adotar uma postura interpretativa, a qual, numa negação ao binômio rural e urbano, os reduza a mera ficção ou mistificação e que, poderia, como alerta Martins (1986), em nome da crítica, lançar mão de uma tentativa de teorização totalizadora que negligencia aspectos importantes do rural e do urbano. A dualidade e o seu produto conceitual que impregna sentidos ao rural representam perspectivas de comprometimento reais, de grupos sociais específicos, bem como de suas demandas de reprodução do espaço, elementos que precisam ser elucidados (Martins, 1986).

Em cada recorte de tempo-espaço da história humana se reproduzem, ontem e hoje, agrupamentos populacionais atuando sobre singulares características morfológicas, com distintas características demográficas e de estratificação social e com processos de especialização de trabalho que correspondem a uma miríade de funções contextuais mais abrangentes. Entre esta vasta diversidade das formas históricas de apropriação do espaço, a ocorrência de contornos do que se demarcaria como a origem histórica do rural é pontuada, cronologicamente, junto com o nascimento das cidades, há cerca de 5.000 a.C. (Favareto, 2007). Segundo esta compreensão, campo e cidade teriam nascido juntos, marcados por um antagonismo binário de recíprocas diferenças.

A sociedade e seus contextos sociais imprimem, no curso histórico das civilizações, diferentes perspectivas, recortes e interações para este par. Resultado de um processo socio-histórico, o par binário rural-urbano apresentará, portanto, padrões e conteúdos cambiantes entre tempos-espaços. Neste artigo, apresentamos uma discussão sobre conceitualizações hegemônicas sobre a relação rural-urbano, com destaque para as determinações conceituais dadas em torno de relações capitalistas condutoras de uma mentalidade urbana de sociedade e seu reflexo nas ciências sociais. Aportando-nos ainda na reflexão crítica presente em estudos sociológicos mais recentes, buscamos analisar a configuração de novos processos sociais não encapsulados na racionalidade capitalista e atualmente em curso na interface rural-urbano.

\section{Capitalismo histórico e evolução da relação rural-urbano}

Abordagens históricas e analíticas dedicadas ao par rural-urbano começam a ser desenvolvidas, segundo Lefebvre (1986[1949]), no momento da Revolução Industrial da economia e da crise do modo de vida camponês com o seu desaparecimento em termos de formas tradicionais. Retomando o trabalho do sociólogo Le Play que inaugurou, na época desta chamada crise do modo de vida camponês, uma linha de obras sociológicas e literárias dedicadas à vida camponesa, Lefebvre assinala que, curiosamente, justo no momento em que ela se esgota, surgem as primeiras narrativas de ideólogos sobre a realidade camponesa:

(...) é preciso esperar a "revolução" industrial da economia e, portanto, o nascente predomínio da indústria sobre a agricultura e da cidade sobre o campo, para que os ideólogos descubram, nela e por ela própria, a realidade camponesa. (Lefebvre, 1986[1949], p. 146)

Um interesse por formas de vida anteriores e exteriores à economia mercantil e industrial que teria surgido justamente quando a burguesia se enriquecia com o desenvolvimento industrial. Lefebvre ainda observa que desde o capitalismo mercantil já se faziam nítidas as transformações exercidas sobre estruturas agrárias, quando a propriedade privada capitalista já iniciara a subordinação de formas anteriores de relação com a terra, como a tribal, o clã, a comunitária e a feudal. Mas seria no período da Revolução Industrial e, mais tarde, com a modernização e a industrialização 
da agricultura que o modo de vida camponês enfim se convulsionaria. As transformações conduzidas pelo capital teriam incidido na predominância de uma lógica individualista, espelho da racionalidade econômica dominante, sobre sistemas tradicionais de produção agrícola, e, com elas, sobre o modo de vida camponês. O camponês, este que "Unas veces cede; otras resiste; hasta su disolución por el individualismo (fundado en la competencia, la economía mercantil etc.)" (Lefebvre, 1975, p. 73), ao fim, perderia por completo a autonomia que o caracterizava. Com a dissolução do modo de vida camponês estaríamos, para Lefebvre (1986), diante do fim do rural, em seu equivalente semântico "comunidade rural".

Marx (1964) e Hobsbawm (1964) são outros autoreschave que propõem análises acerca de correlações entre a expansão do modo de produção capitalista e a afirmação de uma nítida diferenciação ruralurbano. A relação com a natureza, também entendida como meios de trabalho, é um dos pontos centrais da teorização marxiana sobre o surgimento do capitalismo e um componente sempre presente em posteriores tratamentos teóricos sobre a relação rural-urbano no pensamento sociológico moderno.

Em Formações Econômicas Pré-Capitalistas (1964), Marx compreende a separação entre o homem livre e os meios de realização de seu trabalho como a própria separação sociedade/natureza. Tendo em vista a potencialização da reprodução e da acumulação do capital nas relações sociais e de poder capitalistas, 0 trabalhador é reduzido à simples força-de-trabalho, enquanto a propriedade se volta ao controle dos meios de produção de forma divorciada do trabalho (Hobsbawm, 1964).

Ainda que a separação entre a cidade e o campo $^{2}$ fora compreendida como um "elemento fundamental e constante da divisão social do trabalho, bem como sua de expressão, desde o berço da civilização até o século XIX" (Hobsbawm, 1964, p. 31), a distinção entre o campo e a cidade passaria a assumir contornos mais definidos a partir do domínio das relações capitalistas de produção, e sob a crescente especialização social do trabalho agrícola/não agrícola associada à expansão destas relações ${ }^{3}$.

\footnotetext{
2Autores como Araújo (2012) e Rua (2006) traçam distinções entre as categorias cidade/urbano e campo/rural. Cidade e campo seriam, segundo esclarecem estes autores, relativos à dimensão concreta, prático-sensível do espaço geográfico, um conjunto de formas e objetos. As categorias analíticas urbano/rural diriam respeito, por sua vez, à dimensão simbólica, aos significados qualitativos que preenchem de conteúdo e de formas não materiais, ainda que reais e concretas, estes espaços. Em sua abordagem sobre divisão espacial e social do trabalho sob domínio das forças capitalistas, Hobsbawm e Marx privilegiam a dimensão prático-sensível deste processo.

${ }^{3}$ Como sinaliza Hobsbawm: "(...) seu crescimento [do capitalismo] é esboçado por completo, ao menos nas fases iniciais, a partir das cidades" (Hobsbawm, 1964, p. 34)
}

As diferentes formações econômicas précapitalistas de épocas do desenvolvimento histórico por Marx catalogadas como asiática, antiga e feudal, apontariam para a ocorrência de uma espécie de unidade indiferenciada entre cidade e campo. A grande cidade do sistema oriental seria, por exemplo, equivalente a um acampamento principesco superposto a uma macroestrutura econômica baseada em unidades autossuficientes de manufatura e agricultura (Hobsbawm, 1964). Os primeiros avanços da divisão social do trabalho industrial, comercial e agrícola e, nestes, das distinções e oposições entre o campo e a cidade, Marx já identificaria desde a sociedade comunal e a estatal da antiguidade escravista, ainda que consideradas um "estágio não desenvolvido da produção" (Hobsbawm, 1964, p. 29), mas a divisão entre estes espaços se complexificaria somente em um momento seguinte, a partir da conformação de distintas esferas representativas de interesses urbanos e rurais particulares.

0 feudalismo tem em sua primeira fase a área rural como o cenário da história da Idade Média. Em um posterior desenvolvimento, verificamos um giro na relação entre a cidade e o campo com a história da modernidade capitalista resultando, segundo Marx, no processo de urbanização sobressaindo-se sobre área rural, e não na ruralização da cidade como descrito na história antiga e medieval.

Ainda que o capitalismo não tenha surgido via classe artesã urbana, emerge na potencialização desta prodigiosa autonomia da propriedade sobre os bens de produção, na qual o trabalhador não seria, em si, uma condição de produção, apenas seu trabalho o ét. A emergência do capitalismo, e com ele da reafırmação da ideia dos homens enquanto força de trabalho livre - pelo menos potencialmente -, tem como palco, portanto, os cenários urbanos. E a cidade torna-se a protagonista das forças históricas.

Hobsbawm sintetiza tal premissa neste trecho: "O declínio do feudalismo depende, mais uma vez, do advento dos ofícios e do comércio, além da divisão e do conflito entre cidade e campo" (Hobsbawm, 1964, p. 54$)^{5}$. Reforça-se aqui a distinção entre as categorias analíticas campo/cidade à medida que a cidade se enseja como o espaço propício para germinação de relações sociais capitalistas de produção, com as

\footnotetext{
Na explicação da transição do peso da importância dos espaços rurais para os urbanos, apresenta-se como central a figura do artesão medieval, e de sua forma de controle individual sobre os meios de produção desvinculada da integração à terra. A evolução artesanal e urbana do trabalho, assim independente, representaria a emancipação da propriedade sobre os meios de produção, a essência da futura separação entre trabalho e condições objetivas de produção.

Acompanha este processo o progressivo desmantelamento da forma servil de exploração e da estrutura rural a ela associada, com a liberação do camponês como mercado de mão de obra e de consumo e com o surgimento da figura do camponês arrendatário (Hobsbawm, 1964).
} 
consequentes formações de classe, ao longo da história desencadeadas, incidindo em relações hierarquizadas entre o rural e o urbano (Hobsbawm, 1964).

Podemos observar que a distinção analítica estabelecida por Marx, e seguida por Hobsbawm, para a conceituação dos respectivos espaços urbano e rural tem como critério central uma divisão espacial do trabalho na qual caberia à espacialidade rural atividades ocupacionais destinadas à agricultura, e ao urbano, as demais atividades. Ainda na linha desta tipificação que vincula o rural ao agrícola, situamos Lefebvre (1986[1949]), autor que avança nesta proposição partindo da característica atividade agrícola e conferindo demais características espaciais, de paisagem, societárias e comportamentais ao rural, em um amplo, e por vezes ambíguo, conjunto de atributos que delineiam especificidades do rural em contraposição ao urbano.

Essas abordagens clássicas darão suporte a uma corrente de enfoques analíticos posteriores que se dedicam, em variadas nuances, a validar a proposição de que os camponeses conservam um modo de vida diferente, portador de uma autonomia diante da sociedade total ${ }^{6}$. Sob singulares vertentes, estes trabalhos reforçam, em geral, o predomínio de uma perspectiva da relação campo-cidade no sentido de uma progressiva predominância e valorização do urbano. Encontramos, no conjunto dessas perspectivas de leitura sociológica sobre o campo, um eixo comum de representações hegemônicas do urbano sobre o rural, projetadas por sobre um discurso da modernidade que envolve o desenvolvimento histórico do capitalismo e a importância que nela assumem seus processos de industrialização e de urbanização (Wanderley, 2000), como ressalta Moreira (2007):

(...) temos um processo homogeneizador da modernidade ocidental, que teria feito desaparecer o campo e o rural, em especial o rural concebido como imagem de um rural camponês e uma natureza pré-capitalista - o outro da modernidade ao qual se imporiam os poderes urbanos da modernização. Essa narrativa nos lembra da dominação do rural pela indústria e pela cidade (...) o resultado - a industrialização e a urbanização do campo. (Moreira, 2007, p. 69)

O singular modo de vida camponês, assim como de outras formas de organização social comumente interpeladas nas teorizações do pensamento sociológico moderno por um sentido de estranhamento e de inferiorização, termina sendo interpretado a partir

\footnotetext{
${ }^{6}$ Os crescentes níveis de integração ao mercado e as transformações sociais sofridas pelas sociedades rurais teriam deslocado então a condição primeira de "autonomia relativa", típica dos camponeses para uma condição de "agricultores", remetida a um grupo social e a uma classe profissional.
}

de uma compreensão que toma tais construções sociais como elementos residuais de uma marcha em progresso que tende a absorvê-los, homogeneizá-los e extinguilos.

\section{Do rural pré-capitalista ao rural ambiental}

A transição feudalismo-capitalismo significa, para Lefebvre (1986), a chamada crise do rural, acentuada no período da Revolução Industrial quando grandes contingentes populacionais migram em direção às cidades. Da mesma forma que o anonimato literário sobre a realidade do rural teria se desfeito neste incisivo momento de sua crise pelo advento da dinâmica econômica burguesa, a qual, segundo Lefebvre (1975), teria acionado a necessidade de se refletir sociologicamente sobre este espaço, também afirma José de Souza Martins (1986) que a sociologia rural teria surgido com uma motivação similar, justo quando a industrialização ameaça apropriar-se das atividades agrícolas via Revolução Verde. Surge, portanto, como uma ciência que procurava interpretar a realidade sui generis do rural face à expansão de outros formatos de reprodução social de viés hegemonizante. Ambos os autores relacionam a emergência de reflexões teóricas sobre o rural situadas em períodos históricos atrelados a processos de germinação e/ou de expansão das forças capitalista de produção, como na transição entre feudalismo-capitalismo e na intensificação da industrialização via Revolução Verde, evidenciando, assim, a produção teórica sobre o rural com um conhecimento histórica e politicamente contingente.

Em Introdução Crítica à Sociologia Rural, Martins (1986) narra de forma mais detalhada a conformação de compromissos entre ideias-força constituintes do pensamento sociológico e determinadas necessidades, social e politicamente fundamentadas, de legitimação social e expansão do modo de vida capitalista. Segundo o autor, a gênese desta sociologia especial definida como sociologia rural é fruto de uma tentativa de autoexplicação da sociedade capitalista face à existência de formas de vida analiticamente não redutíveis a ela.

A sociologia irá realizar este empenho interpretativo de compreensão do outro, contudo, de forma fidedigna a sua tradição de proposição de pares antagônicos e hierarquizados, em uma estrutura de pensamento que abriga interesses de grupos sociais dominantes. Observamos, com isso, o trilhar de uma narrativa sobre o modo de vida camponês nas representações das ciências sociais sobre o rural que associa características singulares entre o rural e o urbano a 
descontinuidades temporais, por vezes até mesmo retomando componentes caracteristicamente ligados à ordem feudal e ao mundo medieval, retraduzidos e perpetuados, no pensamento moderno, com o objetivo de retratar tais interstícios sociais pré-capitalistas presentes na sociedade capitalista.

A sociologia rural surge, portanto, como um campo de investigação cujo objeto é dotado de estranheza, uma vez que ela se depara com a permanência, na sociedade atual, deste estado de coisas não tipicamente capitalistas do modo de vida camponês. $\mathrm{E}$ como redenção ao rural atrasado, rústico, obsoleto ou medieval, a nascente sociologia rural oferece a távola de salvação de um campo moderno-capitalista afinado à ideologia do progresso, para já não mais camponeses, mas, agora, agricultores empreendedores. Todavia, mesmo este rural, que já fora o espaço da negação - o da não existência de uma série de circunstâncias necessárias à expansão do capital -, reduz-se, mais uma vez, a um espaço negado: modernizado, urbanizase, e por fim, extingue-se junto com seus típicos modos de vida (Martins, 1986).

Seguindo associado a uma temporalidade que não pertenceao presente, ocamponês adquire, em posteriores versões teóricas, atribuições de comportamento que remetem a significados múltiplos, todavia, em geral relacionados a formatos sociorganizativos de um passado pré-capitalista, seja de conotação positiva, tal como um objeto de nostalgia, ou negativa, como um modo de organização social imperfeito, a ser inevitavelmente superado pelo continuum urbano. Tratase de ideias-força que perpassam inúmeros autores, em uma ênfase posta nestes sujeitos sociais do campo no sentido de que transformações em seus modos de vida pudessem representar, mesmo em algumas recentes concepções de viés mais crítico, como a que temos em Martins (1986), a própria extinção do rural e a vitória de um estilo urbano de sociedade?

Em grande parte dessas definições, o que se compreende como rural compartilha desta essência do modo de vida camponês: sua racionalidade socioprodutiva atípica ao capitalismo. O rural tornase sinônimo desta específica forma de organização social, a camponesa, portadora de uma relativa autonomia frente à sociedade capitalista abrangente e ao mercado capitalista nesta sociedade amplificado. $\mathrm{Na}$ representação do discurso científico, o rural frequentemente remete, como vemos, conquanto

${ }^{7}$ Ainda que possamos questionar sua enunciação sobre um possível fim do rural relacionado às transformações sobre um modo de vida camponês a ele atribuído na história do pensamento sociológico, a maior pertinência da análise crítica de Martins (1986) sobre o desenvolvimento da sociologia rural consiste na sua assertiva contribuição sobre como o campo vem sendo sociologicamente associado a construções sociais não resumíveis ao sistema capitalista dominante. associado ao modo de vida camponês, a um espaço não capitalista. Ao menos, o que dele restou, onde não fora ainda desconfigurado por um continuum de expansão urbana ou pela tecnificação moderna da agricultura capitalista.

Sem nos determos, neste momento, na necessária crítica sobre as consequências socioambientais deste processo sobre a realidade em si, propomos a seguinte reflexão: qual é a linha argumentativa que associa o processo de tecnificação do rural à sua urbanização e, portanto, à designação de seu fim? Podemos encontrar pistas que sustentam esta formulação nas raízes epistemológicas do pensamento científico moderno, oriundas do dualismo cartesiano e que envolvem uma abordagem da relação sociedade/natureza clivada por antagonismos entre o ser humano e a natureza. A mesma estrutura de pensamento que concebe complexas unidades em fracionamentos dicotômicos como sujeito/ objeto e sociedade/natureza, e que compreende o rural como o espaço da natureza, e o social como sinônimo do urbano (Martins, 1986; Moreira, 2007).

Natureza tida, no entanto, sob uma significação que abandona suas múltiplas relativizações e redefinições em termos socio-históricos. Uma natureza do pensamento científico moderno que aparece, dessa forma, "como entidade reificada, como coisa alheia à interferência e à produção humanas, como dimensão causal" (Martins, 1986, p. 29).

Enquanto o rural remete a esta concepção de natureza, ao urbano corresponderia, por sua vez, o lócus da institucionalização da técnica e da ciência, com sua respectiva supremacia econômica e simbólica agraciada pela influência da ciência moderna nas sociedades técnico-burocráticas contemporâneas. Ciência e poderes urbanos seriam, portanto, facetas de um mesmo fenômeno confluente da acumulação capitalista, como afirma Moreira (2007):

\footnotetext{
O campo da ciência e da técnica articula capital econômico e simbólico. Expressa interesses econômicos e sociais, sendo, portanto, um campo de disputa da acumulação capitalista. Nesses sentidos, podemos dizer que a ciência moderna compõe, culturalmente, a configuração de poderes urbanos. (Moreira, 2007, p. 86)
}

Neste sentido, segundo esta concepção de que o conhecimento científico estaria sob o fundamento de um mundo urbano em expansão, se deriva a conclusão de que o rural seria sujeito a um processo de supressão de "natureza técnica" (Martins, 1986, p. 33). Mas tal superação técnica do rural diz respeito a um determinado tipo de técnica, seja esta a do pacote 
tecnológico da Revolução Verde, cuja expansão é, por sinal, proveniente de uma cultura de valorização do saber científico moderno ocidental não como apenas uma técnica dentre outras, mas como a melhor técnica ${ }^{8}$. Como se existisse apenas uma técnica e, desta, uma única forma de relação metabólica entre o homem e a natureza, a clivagem sociedade/natureza, técnica/ natureza e, o que mais nos interessa aqui, urbano/rural, resulta, no pensamento sociológico moderno, em uma subsequente polarização: a evolução da distinção entre estes espaços de moderno/tradicional/ para urbano/ ambiental.

O rural agora sob o signo ambiental, em um determinismo ecológico (Martins, 1986) de forma que este se distinguiria do urbano pela preponderância de uma natureza que se diferencia do meio social. Emerge, com isso, um novo rural na modernidade, não aquele camponês e pré-capitalista, mas um rural esvaziado de seus sujeitos e de suas dimensões políticas, na imagem de um espaço harmônico, sem conflitos e tensões sociais, sem disputas pelos usos da terra e do território, o lugar escolhido para a utopia moderna da natureza intocada (Moreira, 2007).

Desde o rural associado às sociedades camponesas tradicionais, e simbolicamente relacionado ao passado e ao atraso, ao rural moderno revestido de um (conservador) discurso ambientalista, perpassam imagens hegemônicas afirmando-se pelas assimetrias de poder que envolvem a legitimação de discursos capitalocêntricos sobre estes espaços.

\section{Estudos críticos sobre o rural}

Recentes perspectivas sobre o rural e as ruralidades de abordagens contemporâneas trazem questões com o potencial de se relativizar narrativas hegemônicas presentes no pensamento sociológico e em consensos sociais sobre o que é o rural. Woods (2009) e Cloke (1997) nos falam sobre estas tendências atuais no âmbito da geografia rural. Estaríamos diante, como expõem, do florescimento de uma gama de questões que envolvem propostas de redefinição e de reconceitualização da ruralidade, tanto em termos de seu foco especial como no sentido de discursos, percepções e vivências sociais associadas a esses espaços.

Trata-se de novas linhas de investigação sobre a reprodução do rural, com diferentes perspectivas nem sempre confluentes, mas que expressam, em suma, um

${ }^{8}$ Valorização social esta baseada na crença de uma ciência neutra, como se fora ideologicamente formulada a partir de agentes abstratos, desprovidos de estruturas e hierarquias de poderes, concebida como se os frutos da produção desta forma específica de conhecimento correspondessem aos interesses de toda a sociedade. rural heterogêneo e multifacetado (Halfacree, 2007; Philo, 1993; Murdoch, 2006). O tema da pluriatividade ilustra bem esta diversidade de propostas interpretativas. A abordagem do geógrafo Rua (2006), por exemplo, centrada na formação de identidades territoriais híbridas rural-urbano, compreende as crescentes transformações do rural como processos integrados a uma lógica mais ampla de expansão do capital e da dimensão simbólica urbana, na qual a pluriatividade tem um papel central, como afirma: "Para nós, a pluriatividade já se integra a uma série de 'urbanidades no rural"' (Rua, 2006, p. 86). Em outra vertente de enquadramento teórico, Halfacree (2007) aponta para um vertiginoso crescimento de atividades artesanais no rural da GrãBretanha, com a presença significativa de atividades especialmente relacionadas a trabalhos de carpintaria e de construção civil, as quais refletem, segundo o autor, práticas e percepções em incremento em um rural "pósprodutivista", orientado para o consumo na forma de lazer, residência e contemplação (Halfacree, 2007).

Neste rural heterogêneo e pós-produtivista, Halfacree (2007) inclui atividades agrícolas desenvolvidas em contestação aos parâmetros da agricultura moderna, como a emergência de projetos de Agricultura Orgânica e Permacultura, e enfoca o que conceitua como "rurais radicais", em construção nos experimentos contraculturais de inúmeros formatos e matrizes ideológicas, ancorados na busca por "sustentabilidade" e/ou de vínculos comunitários.

$\mathrm{Na}$ revisão de conceitos e abordagens preestabelecidas, torna-se notória a interlocução interdisciplinar da geografia rural com áreas de conhecimento como a Ecologia, a Economia e a Antropologia (Woods, 2009; Halfacree, 2007). Referência-chave em abordagens geográficas que considerem a permanência do rural enquanto espaço em transformação, temos, por exemplo, os trabalhos desenvolvidos pela antropóloga Maria José Carneiro (1998, 2002), aportando elementos valiosos para a compreensão da pluriatividade como uma característica que se perpetua historicamente intrínseca ao rural e da ruralidade enquanto um processo em construção cujos signos não devem ser cristalizados em abordagens essencializadas.

Afırmar o que é rural é um ato com implicações políticas, cada definição de rural e de ruralidade contém, em si, intencionalidades, projetos de reprodução social do espaço. Os novos estudos rurais buscam compreender os movimentos destes novos e antigos rurais, não pela simples derrocada do uso de conceitos universais e globais sobre a relação rural-urbano, mas pelo redirecionamento do foco sobre como estes 
espaços são criados, mostrando o poder de certos atores de imporem suas ruralidades sobre outras.

Com seus singulares enfoques, trazem à tona a heterogeneidade e a diferença em coconstrução, as disputas por legitimação dos diferentes discursos e sentidos de rural e de ruralidade. Apresentam reflexões e estudos empíricos que abrangem outros processos e modos de vida nele comportados, diferentes papéis sociais que têm desempenhado no conjunto da sociedade e os possíveis horizontes, no tempo e no espaço, que suas transformações apontam. Preocupados em compreender como o rural-urbano vem produzindo significado e explicação nos estudos sociais e geográficos sobre o rural, acabam por revelar relações de poder presentes, ainda que nem sempre evidentes, nas classificações tipificadas.

Estes trabalhos têm o mérito de trazer à tona a coexistência de variadas versões de rural, bem como de suas disputas por legitimação frente às narrativas hegemônicas, estabelecidas, como vimos, sobre sistemas de produção de conhecimento social e politicamente fundados e compromissados com determinadas estruturas de pensamento. Essa mudança de visão sobre o rural (Goméz, 2001) congrega, entre inúmeros temas, processos de ressignificação do espaço agrário que envolvem um mundo rural onde se incluem atividades ligadas ao seu uso residencial, à presença de empreendimentos de manufatura, industriais e de prestação de serviços, à influência exercida por atividades esportivas e de turismo rural e, como destacamos neste artigo, às experiências sociais engajadas em processos de reorganização da produção, da distribuição e do consumo agrícolas, em contestação às atuais tendências do sistema agroalimentar capitalista dominante. Haveria possíveis assimetrias entre as percepções e ações destes sujeitos sociais e as narrativas hegemônicas sobre o rural?

0 rural é parte de uma forma de construção social da realidade, cuja própria noção é elaborada a partir de determinadas condições e circunstâncias sociais (Martins, 1986), seja nos estudos estatísticos, nas políticas públicas que alimentam estes estudos ou em interpretações provenientes da produção do conhecimento sociológico. Esteja ancorado na polaridade dicotômica de interpretações clássicas, na ideia de um continuum que prevê como tendência das transformações sociais do rural sua superação pelo urbano ou na visão do rural idílico de uma natureza intocada a ser preservada (e apropriada de forma privada) como patrimônio ambiental (Kill, 2016; Moreira, 2007), temos aqui percepções sociais em disputa e incidindo de maneira concreta nas tomadas de decisão que envolvem a reprodução social destes espaços.

Sem a abertura para novas miradas sobre o rural, somos compelimos à reprodução de paradigmas moderno-coloniais de sociedade. Repensar as relações sociais em um horizonte emancipatório envolve também o desafio de se tematizar a relação rural-urbano sob outras perspectivas, para além de abordagens já cristalizadas. Neste caminho, emergem lacunas teóricas que remetem a questionamentos sobre como lidar com a diferença entre rural e urbano de forma não dicotômica e reificada e tampouco remeter o rural a um resquício histórico, ao menos não como na história da modernidade capitalista na qual toda diferença é vista como provisória.

Debruçados sobre esses dilemas, defendemos a necessidade de um método crítico que permita trazer à luz o processo histórico que fecunda tais categorias, e através das quais grupos e indivíduos possam identificar suas vivências espaciais. Com uma abordagem menos instrumental e mais crítica das ciências sociais, tematizar o rural e sua relação com o urbano pode ser uma porta de entrada para se descortinar múltiplas narrativas, inclusive a do discurso científico, e a partir daí repensar a sociedade de outra maneira.

Para compreendermos as diferentes interpretações sobre a relação entre o urbano e o rural que esses outros atores, oriundos do campo e da cidade, carregam, precisamos ainda lançar mão de suportes teóricos de leitura do mundo que comportem a existência, no aqui e agora, de racionalidades socioprodutivas portadoras de elementos atípicos à lógica do acúmulo e da concentração capitalistas. À luz das coordenadas organizativas não capitalistas provenientes destes e outros movimentos, e em diálogo com autores afınados à perspectiva da pluralidade econômica, podemos levantar aspectos para refletir sobre as múltiplas formas de se construir a realidade social e de se pensar politicamente as suas transformações.

\section{0 movimento Community Supported Agriculture e sua interface rural-urbano ético-solidária}

Observa-se, nas últimas quatro décadas, um crescente número de movimentos sociais que buscam reconectar os elos da cadeia alimentar, processo que abrange a exponencial expansão de núcleos Community Supported Agriculture (CSA), ou Agricultura Apoiada pela Comunidade, como o movimento também é conhecido no Brasil. O modelo socio-organizativo CSA surge no Japão em 1971 com o experimento pioneiro do agricultor familiar Yoshinori Kaneko, hoje conhecido 
como o fundador do movimento Teikei, versão japonesa do CSA.

Neste mesmo ano de 1971, outro projeto CSA é identificado na Suíça e na sequência disseminado por diferentes países da Europa. Em 1986, atravessa o continente em direção aos Estados Unidos da América,apresentando nesse país, nos últimos anos, uma de suas mais vertiginosas expressões. Identificamos que, somente nos EUA e no Canadá, existem atualmente mais de 1.720 unidades de produção envolvidas em projetos CSA, reunindo mais de 380 mil pessoas. Alemanha, Reino Unido e França somam hoje, respectivamente, aproximadamente 1.050, $4.800 \mathrm{e}$ 50.000 membros vinculados ao sistema. Na Itália, o CSA, de codinome Gruppi di Acquisto Solidale, é representado por 1.700 experiências, congregando cerca de 51.000 participantes ${ }^{9}$. No Brasil, a implementação de núcleos CSAs encontra-se em franca expansão. De acordo com dados de campo obtidos em 2016, os núcleos de CSA brasileiros congregam, no total, cerca de 1.200 associados. Segundo nossas estimativas, como total mundial o CSA dispunha de aproximadamente 17.110 núcleos com cerca de 41.671 .468 membros vinculados ${ }^{10}$ no ano de 2016.

Mapa 2 - Distribuição de CSAs no mundo - 2016.
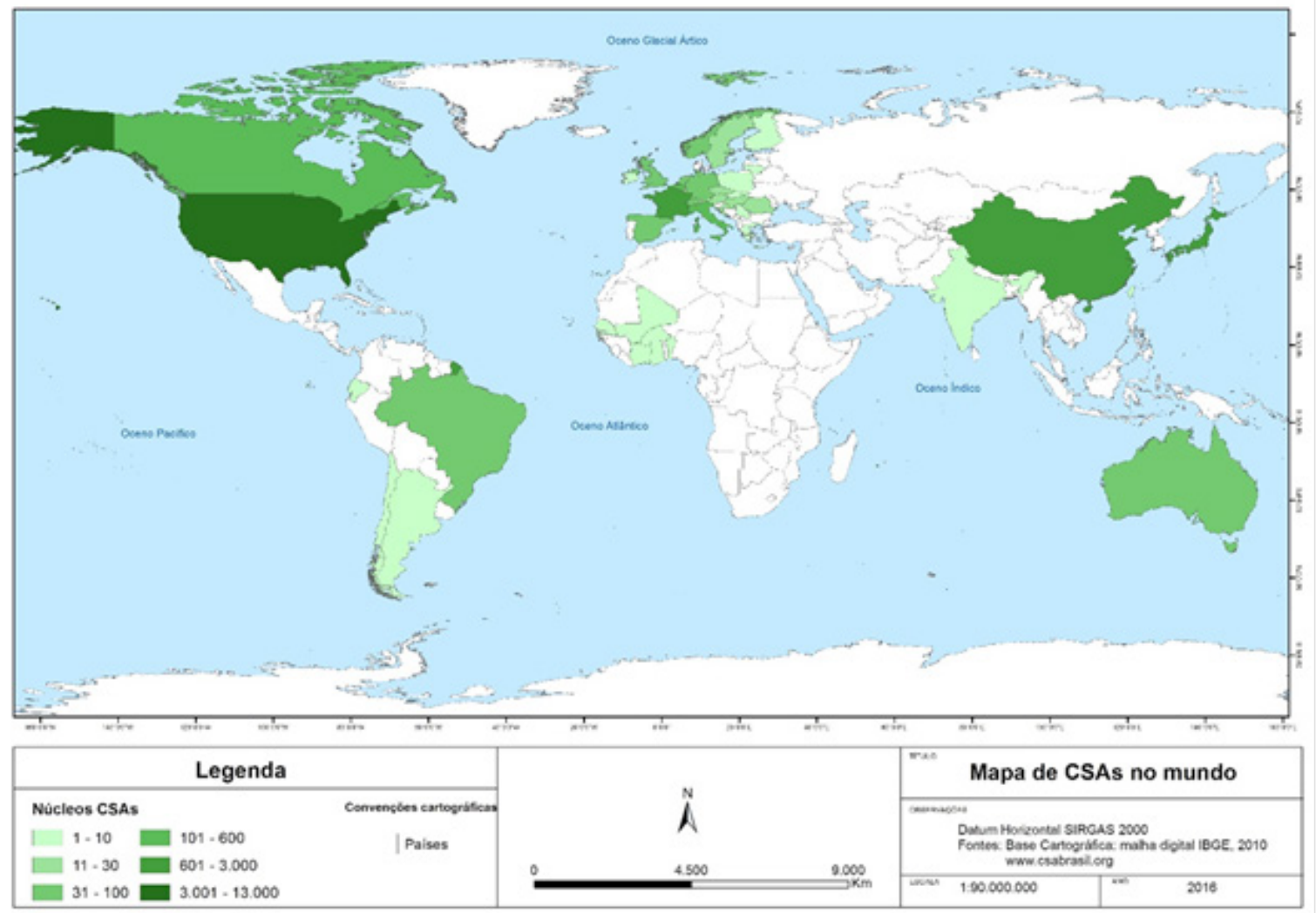

Fonte: ALMB, 2017. 


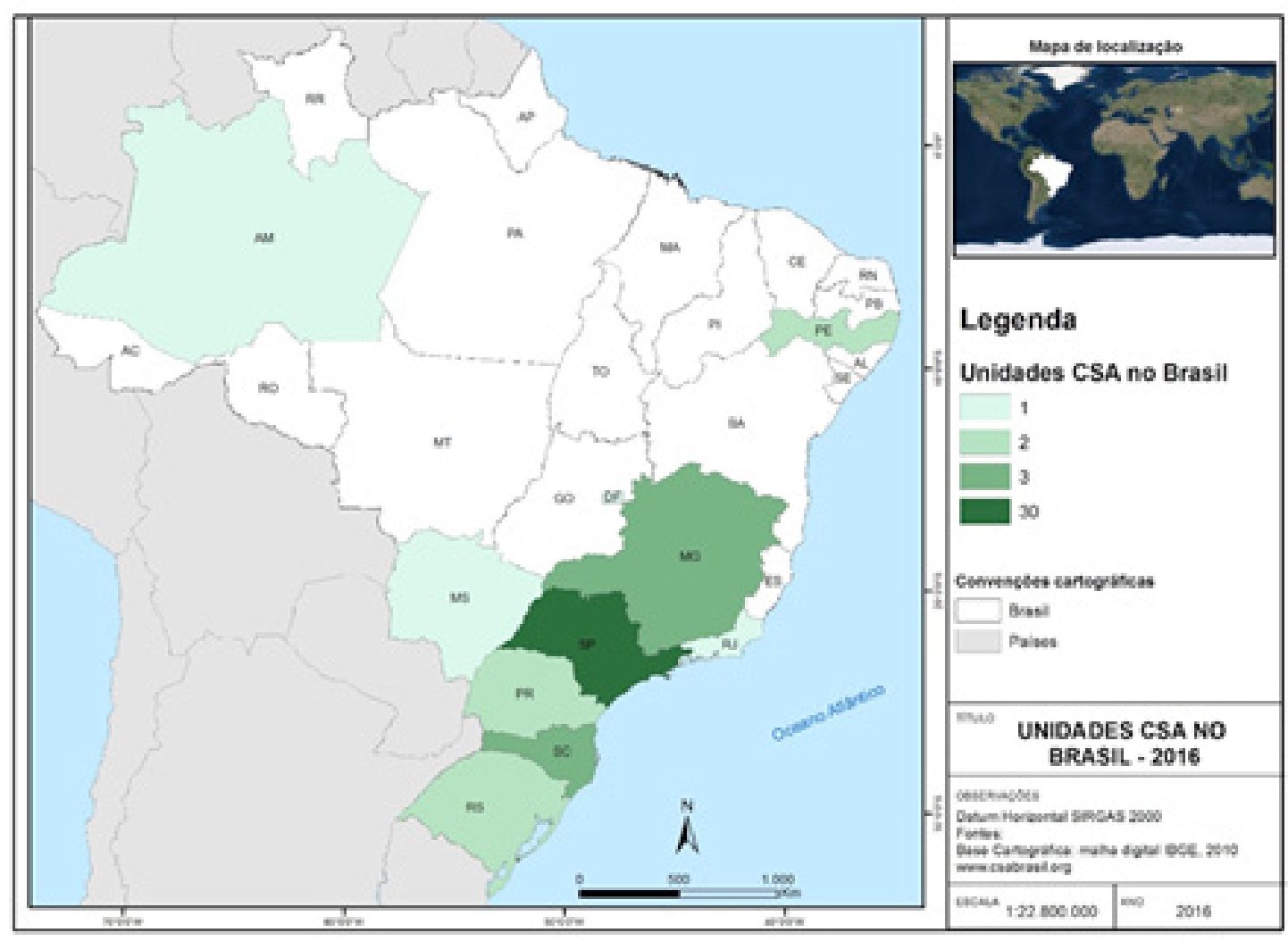

Fonte: ALMB, 2017.

A proposta central da organização de sistemas de produção-distribuição-consumo CSA consiste na realização de um formato associativo de bases comunitárias de forma que os participantes se engajem nos desafios que envolvem todo o sistema produtivo, financiando os custos de produção e auxiliando, ainda, em tarefas coletivas relativas às atividades de manejo e de distribuição. Cotizar despesas, distribuindo a responsabilidade financeira entre todos os associados, assim como colaborar de forma voluntária com demais demandas do sistema produtivo, são ações que compõem uma estrutura organizativa baseada na tática da reciprocidade, estratégia de reprodução social que viabiliza a materialização desta racionalidade de produção-distribuição-consumo ${ }^{11}$ atípica à lógica capitalista.

Quando analisamos o movimento CSA desde um enfoque dirigido aos princípios motivadores que conduzem tais estratégias, destaca-se, logo em primeiro plano, sua proposta de radical ruptura com os circuitos do grande mercado convencional agroalimentar capitalista, como defendem Groh e MacFadden, reconhecidos difusores do projeto e autores do livro Farmers of Tomorrow: Community Supported FarmsFarm Supported Communities (1997). "De um modo ou de outro, as terras agriculturáveis precisam ser tiradas do mercado" (Groh; MacFadden, 1997, p. 126), desafiam os autores. Trata-se, aqui, de um discurso de crítica a determinadas diretrizes do ordenamento agroalimentar capitalista mundial, crítica estabelecida, enquanto prática, através da construção de novas estratégias de abastecimento. Estar fora do mercado significa, para o movimento, organizar a produção de forma a conquistar a maior autonomia possível em relação ao processo de acúmulo e concentração dos grandes mercados agroalimentares capitalistas, catalisadores da crescente mercantilização e especulação da terra, do trabalho e do dinheiro (Polanyi, 2000, 2012). 
Figura 1 - Dia de Campo, CSA SpeiseGut, Berlim, Alemanha.

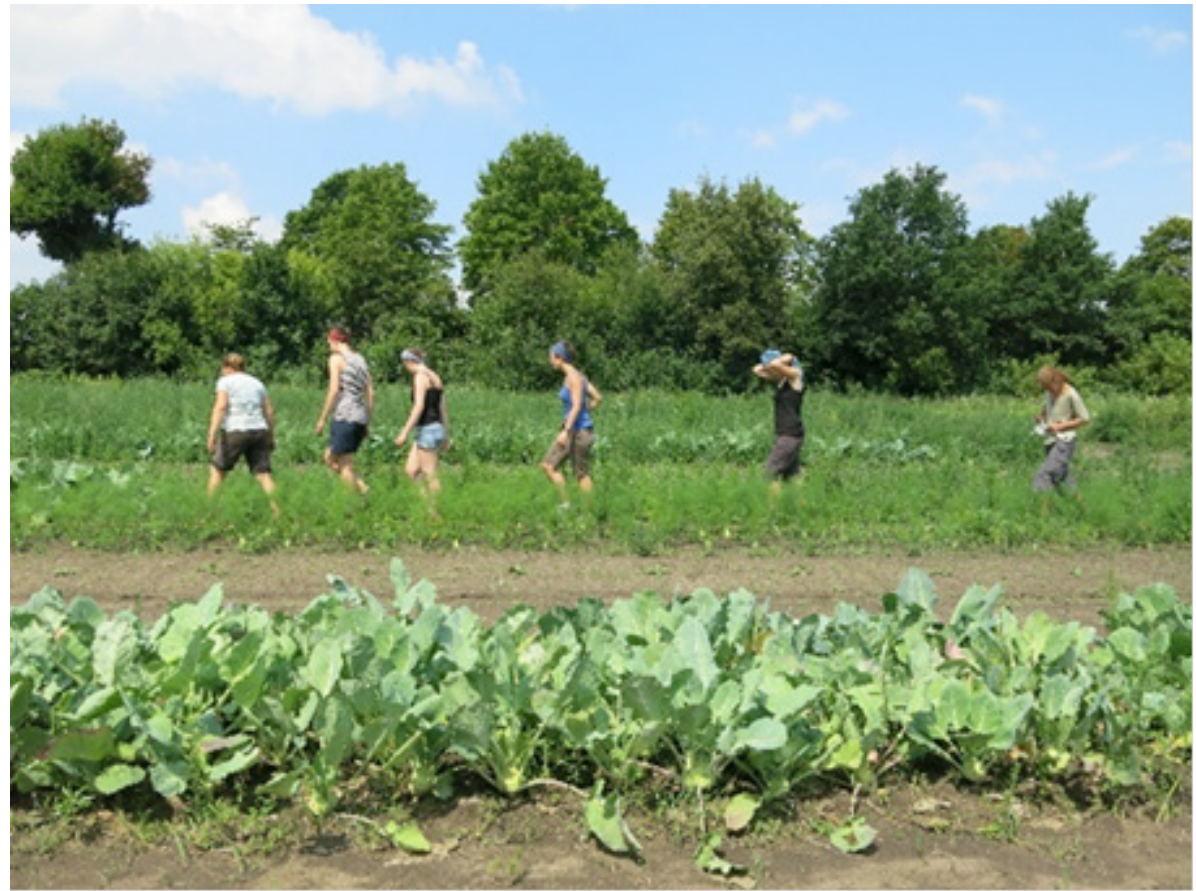

Fonte: ALBM, agosto de 2014, Spandau, Alemanha.

Em paralelo à adoção de práticas de manejo agrícolas de bases ecológicas, as quais também identificamos neste horizonte de busca por autonomia, a economia associativa praticada pelos membros CSA pode ser vista como uma das mais criativas faces de sua expressão contestatória. Em realidade, menos as orientações de seus encaminhamentos técnicos de cultivo e mais suas estratégias socio-organizativas são as características que melhor definem o CSA, distinguindo-o de demais movimentos de agricultura alternativa surgidos em décadas anteriores. A constituição deste formato diferenciado de abastecimento aciona uma profunda reconfiguração de uma série de condutas particulares e coletivas, envolve aspectos relacionados não apenas a práticas de consumo, mas também de gestão e de logística de sistemas agroalimentares.

Um dos princípios centrais do movimento CSA é a busca por uma relativização da oposição consumo/ produção. Todos os membros são considerados coagricultores e coconsumidores ${ }^{12}$. Trata-se de um

pressuposto, presente no conjunto das experiências CSAs ao redor do mundo, que sintetiza sua originalidade organizativa, bem como sua relevância ética.

Nos sistemas de táticas e estratégias mobilizados pelos atores sociais do movimento CSA, observamos a construção de um processo de redimensionamento dos atributos de qualificação social do alimento, agora investido de outros valores socioculturais. Nesta experiência, novas valorações acerca da alimentação são legitimadas e destacadas como importantes. Para além das qualidades nutricional, sanitária e gustativa que dizem respeito a uma motivação de consumo atrelada a uma satisfação pessoal, torna-se um componente-chave de suas estratégias a valoração moral do alimento. Mais do que uma alimentação adequada, esses atores buscam construir sociabilidades saudáveis, equilibradas, não contaminadas pela marca da exploração do homem pelo homem.

A qualidade ética do alimento torna-se, assim, - elemento a ser viabilizado em suas práticas socioprodutivas, tal como numa crítica política, traduzida em ações práticas, sobre a crescente fetichização da mercadoria na modernidade capitalista. Cristovam Buarque (1995) nos fala sobre uma transição, em curso, de uma modernidade técnica para uma modernidade ética, quando as racionalidades econômicas sejam definidas não somente por um ideal de eficiência técnica, mas pelos valores éticos mobilizados pela sociedade.

No caso da experiência CSA, os atores se engajam no movimento buscando reafirmar valores éticos de solidariedade, postos em marcha por meio de práticas de reciprocidade. 0 conjunto de técnicas de produçãodistribuição por eles articulado não diz respeito, portanto, a uma técnica capitalista, mas a um construto de tecnologias sociais de uma outra racionalidade socioprodutiva, de bases horizontais e eticamente mediada. 
O rural, de acordo com o pensamento sociológico tradicional, seria suprimido pela técnica capitalista científica moderna. Mas nem toda técnica é capitalista. Os arranjos socioprodutivos construídos por esses sujeitos recriam ruralidades e conexões entre o rural e o urbano, reforçando vínculos e contrariando interpretações hierarquizadas sobre a relação entre esses espaços. Sob os pressupostos de uma ética solidária, os habitantes da cidade - numa leitura sociológica clássica, os residentes deste lócus por excelência da técnica - passam a considerar o papel do rural frente às engrenagens do sistema técnico em que vivem.

Temos, com isso, uma visão ecossistêmica que se retraduz, na perspectiva da relação sociedade-natureza, também sob a categoria rural-urbano. Segundo entrevistas semidirigidas realizadas com participantes CSA no Brasil e na Alemanha, as motivações para ingresso no movimento remetem à ideia de uma possibilidade de contato com a natureza, à aproximação com o campo a este retorno a bases naturais.

A percepção social do campo reveste-se, assim, pelo sentido da vivência de um espaço natural, de uma natureza que não se exprimiria na urbe, uma vez esta última reduto da técnica e do artificial. Mas a categoria rural-urbano, neste movimento social também representada sob o signo natureza/sociedade, não se reproduz tal como nas tendências interpretativas sociológicas que designam ao rural o ambiente protegido da ação humana. No CSA o rural é tomado por significados que ultrapassam a visão ambiental na qual a atividade agrícola incompatibiliza-se com propostas de um rural não produtivo a ser preservado. Sob um sentido socionatural, o ecossistema rural é construído na interseção natureza-trabalho humano, com a promoção de uma agricultura agrobiodiversa ${ }^{13}$ que não exclui, mas, pelo contrário, se reproduz através do uso produtivo do solo. Observamos, ainda, uma vivência estética da natureza, a ida ao campo como uma possibilidade de sensibilização corpóreo-sensorial do mundo. 0 toque na terra, o trabalho ao ar livre, o movimentar o corpo, o rural torna-se para estes atores a vivência de uma

Figura 2 - Loteamento urbano no município de Botucatu/SP. a cidade não natural.

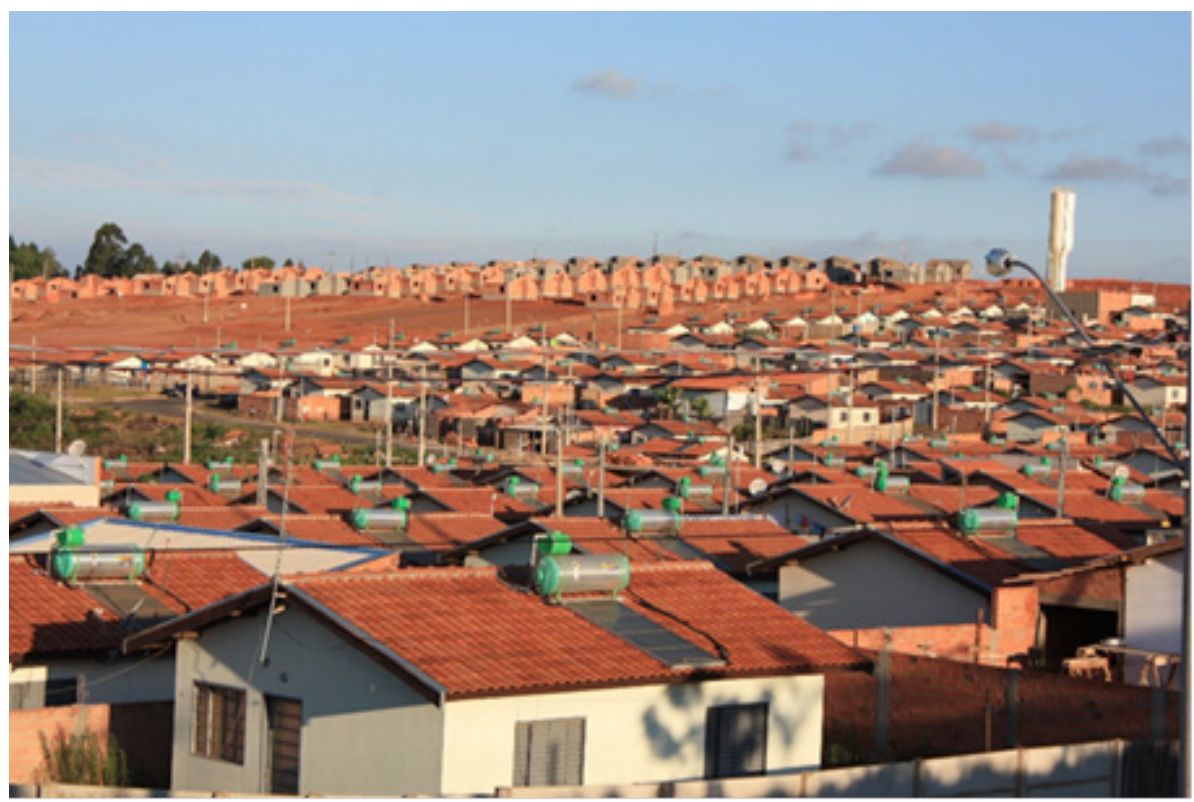

Fonte: Fonte: ALBM, julho de 2012, Botucatu, Brasil. 
outra sensibilidade corpórea latente, como nos conta esta entrevistada em Freiburg, na Alemanha, ao ser questionada sobre o que a levou a se tornar participante do CSA: "Eu só posso te dizer, eu li algo e eu acho que, 'sim!', é isso que eu quero fazer. Eu sinto isso em meu coração, em meu corpo" (Coagricultora, Freiburg, agosto de 2014). Podemos identificar aqui a permanência da uma concepção binária entre urbano e rural, uma vez que segue pertencente ao segundo o espaço idealizado da natureza. Mas percebemos, também, uma releitura da categoria natureza, não aquela natureza intocada como na visão preservacionista clássica. Nesta configuração socializada do que se entende como natural, o homem do campo, ou aquele em contato produtivo com o campo, torna-se um elemento importante que compõe esta natureza.

Figura 3 - Natureza rural: CSA em Osnabrück, Alemanha.

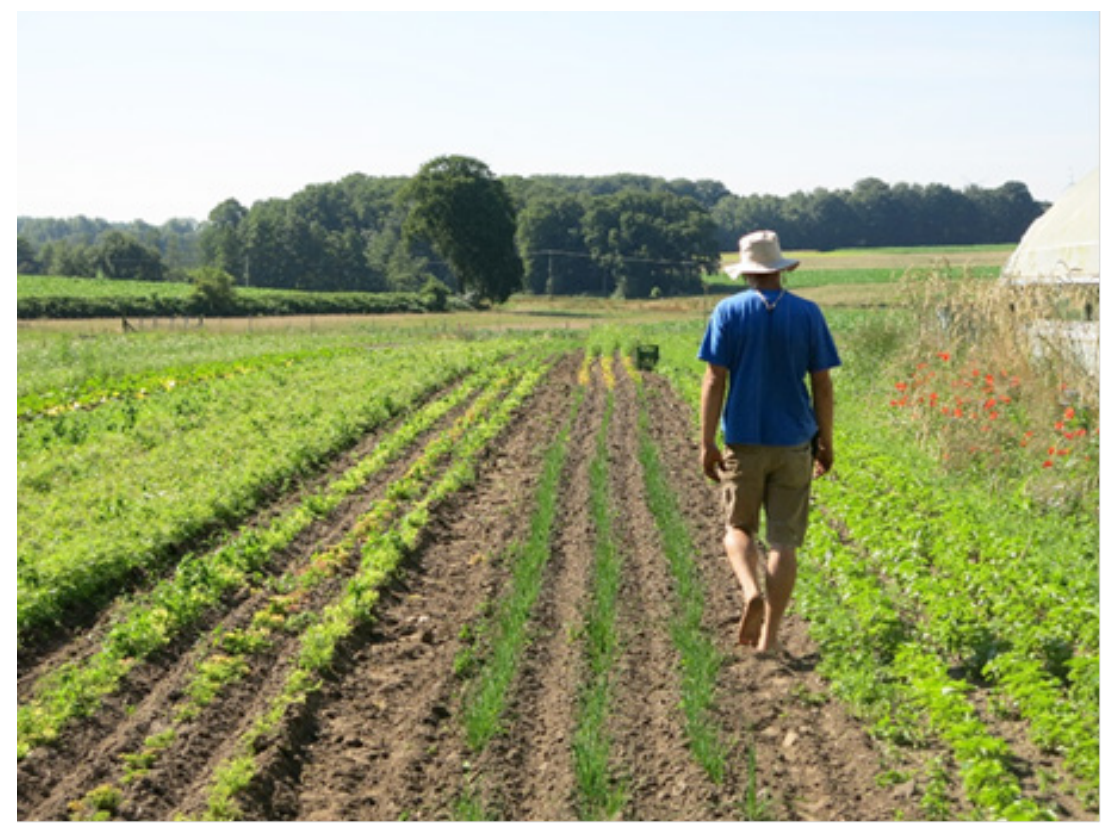

Fonte: ALBM, agosto de 2014.

A valoração do rural percorre, portanto, esta concepção que reifica seu espaço como a alteridade do artificial meio urbano, todavia, enquanto uma natureza portadora de uma outridade que é sobremodo humana. Humana e repleta de sujeitos que conformam o outro de um formato organizativo baseado em relações éticosolidárias de reciprocidade. Nas experiências CSA, não se trata, assim, de identidades mescladas, de um tendencial hibridismo cultural, ou de uma bivalência profissional como no trabalho part time rural-urbano ${ }^{14}$.

A ética solidária exercitada por estes autores considera a existência do outro e traz para perto de si suas demandas e necessidades existenciais, sem, todavia, homogeneizá-lo, como o seria a partir de uma leitura evolucionista ou, em uma visão ageográfica, que desconsiderasse a presença de diferentes formas de organização socioespacial entre os respectivos

${ }^{14}$ Como sugerem os processos de trabalho part time investigados pelos autores italianos Mingione e Pugliese (1987), entre outros. recortes. A vivência da totalidade não é necessariamente totalitarista. 0 diferente permanece como algo a ser valorado e socialmente valorizado, não como reduto, mas como o elo de um atual e importante encadeamento de relações recíprocas rural-urbano.

\section{Considerações finais}

A natureza rural de que anseiam os atores CSA é vivida no seio do compartilhamento do suporte ao trabalho agrícola, uma natureza que é também técnica, que não exclui a sociedade e, para além disso, tornase o veículo para relações societárias baseadas em racionalidades econômicas éticas e solidárias. Como vemos, nem toda técnica é capitalista e tampouco urbana. Assumindo-se este pressuposto, observamos um processo contrário à idealização do rural enquanto um resíduo a ser suprimido. De maneira oposta ao 
discurso do fim do rural, observamos a construção social de um sistema sociotécnico que legitima sua afırmação no momento presente, como uma chave fundamental frente aos desafios que envolvem a condição de sersolidariamente-em-sociedade, hoje e no futuro.

0 estabelecimento de regimes agroalimentares capitalistas inferiu transformações sobre modos de vida no campo e na cidade, tanto pela promoção de modelos de desenvolvimento agrícola-agrários como pela instauração de ideologias alimentares, dinâmicas que influem, em conjunto, em todo um processo histórico de desagregação e hierarquização da relação rural-urbano. Mas numa contrarresposta crítica, movimentos sociais como o CSA vêm propor, nos cinco continentes do mundo, uma tomada de posicionamento ético-político acerca desta relação.

Procuramos destacar, neste artigo, a sinergia destas práticas éticas de reprodução econômica da vida quotidiana com suas complexas conexões entre escalas macro e micro; entre realização econômica e imaginários ético-políticos; entre produção e consumo; bem como entre o urbano e o rural. As relações protagonizadas por esses sujeitos ultrapassam as clássicas e simplificadoras formas de se conceber a sociedade a partir de pares binários dicotômicos, essencializados, reducionistas e divergentes entre si. A forma como esses atores sociais transitam e ressignificam essas dimensões comprova a existência não apenas de um rural, mas de inúmeras ruralidades, cujas concepções e articulações com o urbano refletem, em suma, horizontes societários. 0 pensar da sociedade urbana sobre este outro diferente, o espaço rural, espelha a forma como ela compreende a si mesma e a sua visão de mundo, sendo possível rastrear matrizes balizadoras de valores e ideais políticos pelas concepções de rural que seus agentes reproduzem. 


\section{Referências}

ARAÚJJO, James Amorim (2012). Sobre a cidade e o urbano em Henri Lefebvre. GEOUSP - Espaço e Tempo, São Paulo, n. 31 , p. 133-142.

BELL, Michael M. (1966). The fruit of difference: the rural-urban continuum as a system of identity. Rural Sociology, v. 31, n. 4, p. 449-457.

BUARQUE, Cristovam (1995). A cortina de ouro: os sustos do final do século e um sonho para o próximo. São Paulo: Paz e Terra.

CARNEIRO, M. J. (1998). Ruralidade: novas identidades em construção. Estudos Sociedade e Agricultura, número 11, outubro, p. 53-75.

(2002). Multifuncionalidade da agricultura e ruralidade: uma abordagem comparativa. In: MOREIRA, R. J.; COSTA, L. F. de C. (orgs.). Mundo Rural e Cultura. Rio de Janeiro: Mauad.

CLOKE, P. (1997). Country Backwater to virtual village. Rural studies and "the cultural turn". Journal of Rural Studies, vol. 13, n. 4, p. 367-375.

FAVARETO, Arilson da Silva (2007). A longa evolução rural-urbano. Ruris, vol. 1, n. 1, p. 157-190.

GÓMEZ, Sérgio E. (2001). ¿Nueva Ruralidad? Un aporte al debate. Estudos sociedade e agricultura, n. 17, outubro, p. 5-31.

GROH, T.; MCFADDEN, S. (1997). Farmers of Tomorrow Revisited: Community Supported Farms-Farm Supported Communities. United States: Biodynamic Farming and Gardening Association, Kimberton PA.

HALFACREE, Keith (2007). Trial by space for a 'radical rural': introducing alternative localities, representations and lives. Journal of Rural Studies 23.p. 125-141

HOBSBAWM, Eric (1964). In: MARX, K. Formações Econômicas Pré-Capitalistas (Introdução). Rio de Janeiro: Paz e Terra.

KILL, Jutta (2016). Valoración económica de la naturaleza y pago por servicios ambientales: ¿reconocer el valor de la naturaleza o asignarle un precio a la destrucción? Disponível em: <https://mx.boell.org/sites/default/files/jutta_kill_text_final_04.pdf>. Acessado em: junho de 2016.

LEFEBVRE, Henri (1975). De lo rural a lo urbano. Barcelona: Lito-Fisán.

(1986[1949]). Problemas de Sociologia Rural (1949). In: MARTINS, José de Souza. Introdução Crítica à Sociologia Rural. São Paulo: Editora Hucitec.

MARTINS, José de Souza (1986). Introdução Crítica a Sociologia Rural. São Paulo: Editora Hucitec.

MARX, K. (1964). Formações Econômicas Pré-Capitalistas. Rio de Janeiro: Paz e Terra.

MARX, K. (2013 [1867]). O Capital, Livro 1. São Paulo: Boitempo Editorial.

MINGIONE Enzo; PUGLIESE Enrico (1987). A difícil delimitação do "Urbano e do Rural": alguns exemplos e implicações teóricas. Revista Crítica de Ciências Sociais, n. 22, abril, p. 83-99.

MOREIRA, Roberto José (2007). Configuração de poderes urbanos-rurais: fragmentos de discursos e práticas. In: MARAFON, Gláucio José; RUA, João; RIBEIRO, Miguel Angelo (orgs.). Abordagens Teórico-Metodológicas em Geografia Agrária. Rio de Janeiro: Ed UERJ.

MURDOCH, Jonathan (2006). Networking rurality: emergent complexity in the countryside. In: CLOKE, P.; MARSDEN, T.; MOONEY, P. (orgs.). Handbook of rural Studies. London - Tousand Oakes - New Delhi: SAGE Publication.

PHILO, Chris. Postmodern Rural Geography? A replay to Murdoch and Pratt. Journal of Rural Studies. Vol. 9, N. 4, p. 429436, 1993. Printed in Great Britain.

POLANYI, K. (2000). A grande transformação: as origens de nossa época. 2. ed. Rio de Janeiro: Compus. 
(2012). A subsistência do homem e ensaios correlatos. Rio de Janeiro: Contraponto.

RUA, João (2006). Urbanidades no rural: o devir de novas territorialidades. Campo território: Revista de Geografia Agrária, Uberlândia, v. 1, n. 1, p. 82-106, fev.

SPOSITO, Maria Encarnação Beltrão; WHITACKER, Arthur Magon (2006). Cidade e Campo: relações e contradições entre o urbano e o rural. São Paulo: Expressão Popular.

WANDERLEY, Maria de N. B. (2000). A emergência de uma nova ruralidade nas sociedades modernas avançadas, 0 "rural" como espaço singular e ator coletivo. Estudos Sociedade e Agricultura, n. 15, outubro, p. 87-146.

WOODS, Michael (2009). Rural Geography: blurring boundaries and making connections. Progress in Human Geography, Londres: Sage Publications, n. 6, ano 33, p. 849-858. 